\title{
Challenges in standardization of blood pressure measurement at the population level
}

\author{
Hanna Tolonen ${ }^{1 *}$, Päivikki Koponen ${ }^{1}$, Androniki Naska ${ }^{2}$, Satu Männistö ${ }^{1}$, Grazyna Broda ${ }^{3 \wedge}$, Tarja Palosaari ${ }^{1}$, \\ Kari Kuulasmaa ${ }^{1}$ and for the EHES Pilot Project
}

\begin{abstract}
Background: Accurate blood pressure measurements are needed in clinical practice, intervention studies and health examination surveys. Blood pressure measurements are sensitive: their accuracy can be affected by measurement environment, behaviour of the subject, measurement procedures, devices used for the measurement and the observer. To minimize errors in blood pressure measurement, a standardized measurement protocol is needed.

Methods: The European Health Examination Survey (EHES) Pilot project was conducted in 2009-2012. A pilot health examination survey was conducted in 12 countries using a standardized protocol. The measurement protocols used in each survey, training provided for the measurers, measurement data, and observations during site visits were collected and evaluated to assess the level of standardization.

Results: The EHES measurement protocol for blood pressure was followed accurately in all 12 pilot surveys. Most of the surveys succeeded in organizing a quiet and comfortable measurement environment, and staff instructed survey participants appropriately before examination visits. In all surveys, blood pressure was measured three times, from the right arm in a sitting posture. The biggest variation was in the device used for the blood pressure measurement.

Conclusions: It is possible to reach a high level of standardization for blood pressure measurements across countries and over time. A detailed, standardized measurement protocol, and adequate training and monitoring during the fieldwork and centrally organized quality assessment of the data are needed. The recent EU regulation banning the sale of mercury sphygmomanometer in European Union Member States has set new challenges for the standardization of measurement devices since the validity of oscillometric measurements is device-specific and performance of aneroid devices depends very much on calibration.
\end{abstract}

Keywords: Blood pressure, Surveillance, Methodology

\section{Background}

High blood pressure is a major risk factor for vascular disease, such as ischaemic heart disease and stroke. High blood pressure can be lowered by lifestyle changes and medical treatment. Small changes in the average blood pressure values of the population may be of considerable importance to public health [1]. Accuracy of blood pressure measurement is important in clinical practice, intervention studies and health examination surveys. Measured blood pressure is influenced by the measurement environment,

\footnotetext{
* Correspondence: hanna.tolonen@thl.fi

Deceased

'Department of Health, National Institute for Health and Welfare, Helsinki,

Finland

Full list of author information is available at the end of the article
}

behavior of the subject, measurement protocol, device used for the measurement, and the observer.

Environmental factors such as the temperature of the room in which the blood pressure is measured and possible disturbance (eg. traffic noise, telephone ringing, and people entering the room) during the measurement may affect the outcome [2]. Activities such as strenuous physical exercise, smoking, heavy meals or drinking of coffee, tea or alcohol, or an uncomfortably full bladder are known to alter blood pressure [3,4]. The measurement protocol, the detailed instructions for how the blood pressure should be measured, has a significant role in the accuracy of the blood pressure results. Resting time before measurements, the arm used for the measurement, 
posture of the subject (sitting or supine) and the arm during the measurement, support of the back and feet, crossed legs, placement of the cuff over the clothing or on the bare arm, and talking during the measurement each affect the outcome [3-12].

The simple mercury sphygmomanometer has long been considered as a 'gold standard' for blood pressure measurement. Commonly used alternatives for the mercury sphygmomanometer are oscillometric devices, which should prevent the observer error present when the mercury sphygmomanometer is used. Validation protocols have been defined to ensure that oscillometric devices measure accurately in comparison with the mercury sphygmomanometer. It is important to ensure that devices used have passed the validation against at least one of the following: the British Hypertension Society protocol [13], International protocol [14] or Association for the Advancement of Medical Instrumentation (AAMI) protocol [15]. Regardless of the type of blood pressure measurement device, selection of the correct cuff size is important [11] and when the auscultation method is used, the side of the stethoscope used may have an effect on the outcome [16,17]. For all device types, mercury and aneroid sphygmomanometers, and oscillometric devices, calibration error may also bias the results $[18,19]$.

Common observer errors in the auscultation method are systematic error, terminal digit preference and observer prejudice or bias [20]. Systematic error occurs in auscultation method when the observer does not hear well enough, or has slow reactions to auditory and visual cues. There may also be problems in the interpretation of the Korotkoff sounds [21]. Theoretically it is expected that terminal digits of the blood pressure readings are evenly distributed. When mercury sphygmomanometers are used, there should be equal proportions of terminal digits of $0,2,4,6$, and 8 and for oscillometric devices terminal digits from 0 to 9 . Terminal digit preference is a common problem in both clinical practice and in epidemiological studies. Often the preference is observed for a terminal digit of zero. Some observers also have a tendency to avoid or prefer certain blood pressure readings or, when sequential readings are taken, to provide identical readings [22-24].

Table 1 summarizes reported effects of different factors influencing observed systolic and diastolic blood pressure values. The effects vary from 1-2 mmHg up-to $20-$ $50 \mathrm{mmHg}$. These can have a large effect on treatment decisions. They can also bias substantially population estimates of blood pressure levels and hypertension prevalence derived from health examination surveys. Using data from Canadian and UK surveys, it has been shown that overestimation of systolic blood pressure by 3 and $5 \mathrm{mmHg}$ increases the number of persons classified as hypertensive by $24 \%$ and $43 \%$ respectively; underestimation by the same amount misses 19\% and $30 \%$ of persons with hypertension [25]. Without proper standardization of the measurements, true population level changes may be mixed up with the effects of measurement error.

To minimize errors in blood pressure measurement, standardized measurement protocols have been proposed, for example by the European Society of Hypertension [11] and the American Heart Association [26]. These protocols are for clinical measurement of blood pressure. There are also international blood pressure measurement protocols for epidemiological studies, proposed by World Health Organization (WHO) MONICA Project [27], WHO in the Cardiovascular Survey Methods [28] and the European Health Examination Survey (EHES) Project [29].

The aim of this paper is to evaluate the level of standardization of blood pressure measurement in the EHES Pilot Project.

\section{Methods}

\section{European health examination survey}

EHES is a collaboration for standardizing national health examination surveys in Europe. The EHES Pilot Project was conducted in 2009-2012. The EHES Reference Centre (EHES RC) was established to coordinate the activities. The EHES RC prepared the European level standardized health examination survey (HES) protocol; provided support to the countries in planning and preparing their national HESs; organized European level training and provided training materials; organized external quality assessment; and evaluated the survey outcomes.

Twelve countries (Czech Republic, Finland, Germany, Greece, Italy, Malta, the Netherlands, Norway, Poland, Portugal, Slovakia and UK/England) planned and prepared for their national HES and conducted a pilot survey to test the feasibility of their survey protocol [30]. In four pilot countries (Germany, Italy, Netherlands and UK/England), a full-size national HES was on-going. In these countries, the aim was to evaluate how the EHES protocols could be incorporated into the on-going HES.

These pilot surveys, consisting in total of 4127 participants aged 25-64 years, were conducted in geographically defined populations. The pilot surveys were not nationally representative. Each survey was conducted by a local survey team after approval from the national/ regional ethics committee (Appendix 1). Written informed consent was obtained from the survey participants.

\section{Standardized protocol}

The EHES Manual provides standardized protocols for conducting HESs, including planning, running the fieldwork and reporting [31,32]. The blood pressure measurement protocol is based on three sequential measurements, one minute apart, from the right arm in a sitting posture. 
Table 1 Reported effect of different factors of observed blood pressure levels

\begin{tabular}{|c|c|c|c|}
\hline Related to & Factor & $\begin{array}{l}\text { Effect on systolic blood } \\
\text { pressure }(\mathrm{mmHg})\end{array}$ & $\begin{array}{l}\text { Effect on diastolic blood } \\
\text { pressure }(\mathrm{mmHg})\end{array}$ \\
\hline $\begin{array}{l}\text { Environment in which } \\
\text { measurement is conducted }\end{array}$ & $\begin{array}{l}\text { Cold room vs. comfortable room } \\
\text { temperature [2] }\end{array}$ & $\Uparrow 14 \mathrm{mmHg}$ & $\Uparrow 15 \mathrm{mmHg}$ \\
\hline \multirow[t]{5}{*}{ Person being measured } & Full bladder $[3,4]$ & $\begin{array}{l}\Uparrow 10-15 \mathrm{mmHg} \text {, in case of } \\
\text { uncomfortably distended bladder }\end{array}$ & $\begin{array}{l}\Uparrow 10 \mathrm{mmHg} \text {, in case of uncomfortably } \\
\text { distended bladder } \Uparrow 40 \mathrm{mmHg}\end{array}$ \\
\hline & & $\Uparrow 50 \mathrm{mmHg}$ & \\
\hline & $\begin{array}{l}\text { Heavy physical exercise before } \\
\text { measurement [3] }\end{array}$ & $\Downarrow 18-20 \mathrm{mmHg}$ & $\Downarrow 7-9 \mathrm{mmHg}$ \\
\hline & Heavy meal before measurement [3] & $\Downarrow 20 \mathrm{mmHg}$ & $\Downarrow 20 \mathrm{mmHg}$ \\
\hline & Smoking before measurement [3] & $\Uparrow 10 \mathrm{mmHg}$ & $\Uparrow 8 \mathrm{mmHg}$ \\
\hline \multirow[t]{9}{*}{ Measurement procedure } & $\begin{array}{l}\text { Not resting at least } 5 \text { min before } \\
\text { measurement [5] }\end{array}$ & $\Uparrow 10-20 \mathrm{mmHg}$ & $\Uparrow 14 \mathrm{mmHg}$ \\
\hline & Left arm vs. right arm [6] & $\Downarrow 1-3 \mathrm{mmHg}$ & $\Uparrow 1 \mathrm{mmHg}$ \\
\hline & Supine vs. sitting [7] & $\Uparrow 3-10 \mathrm{mmHg}$ & $\Uparrow 1-5 \mathrm{mmHg}$ \\
\hline & Back/feet unsupported vs. supported [4] & 介 $5-15 \mathrm{mmHg}$ & $\Uparrow 6 \mathrm{mmHg}$ \\
\hline & $\begin{array}{l}\text { Arm unsupported during the measurement } \\
\text { vs. arm supported }[4,11]\end{array}$ & $\Uparrow 1-7 \mathrm{mmHg}$ & $\Uparrow 5-11 \mathrm{mmHg}$ \\
\hline & Legs crossed vs. not crossed [8] & $\Uparrow 5-8 \mathrm{mmHg}$ & $\Uparrow 3-5 \mathrm{mmHg}$ \\
\hline & $\begin{array}{l}\text { Talking during the measurement vs. } \\
\text { silent }[4,12]\end{array}$ & $\Uparrow 17 \mathrm{mmHg}$ & $\Uparrow 13 \mathrm{mmHg}$ \\
\hline & $\begin{array}{l}\text { Arm below heart level vs. arm at the } \\
\text { heart level [9-11] }\end{array}$ & $\Uparrow 10 \mathrm{mmHg}$ & $\Uparrow 10 \mathrm{mmHg}$ \\
\hline & Cuff over clothing vs. cuff on bare arm [4] & $\Uparrow 5 \mathrm{mmHg}$ & not reported \\
\hline \multirow[t]{5}{*}{ Device } & Cuff too large [11] & $\Downarrow 10-30 \mathrm{mmHg}$ & $\Downarrow 10-30 \mathrm{mmHg}$ \\
\hline & Cuff too small [11] & $\Uparrow 3-12 \mathrm{mmHg}$, in obese persons & $\Uparrow 2-8 \mathrm{mmHg}$, in obese persons \\
\hline & & $\Uparrow 30 \mathrm{mmHg}$ & $\Uparrow 30 \mathrm{mmHg}$ \\
\hline & $\begin{array}{l}\text { Diaphragm of stethoscope vs. bell } \\
\text { (auscultation method used) }[16,17]\end{array}$ & $\Downarrow 0-2 \mathrm{mmHg}$ & $\Downarrow 0-2 \mathrm{mmHg}$ \\
\hline & Calibration error $[18,19]$ & $0-5 \mathrm{mmHg}$ & $0-5 \mathrm{mmH}$ \\
\hline
\end{tabular}

$\Uparrow$ Arrow upwards: increases observed blood pressure level; $\Downarrow$ arrow down wards: decreases observed blood pressure level.

The survey participant should be sitting on a chair with the participant's feet firmly on the floor and not crossed, and with their back supported by the chair. The participant's arm should be resting, palm up, on a desk, table or arm rest of the chair so that the antecubital fossa is at the heart level. Before measurement, the participant is asked to remove all the clothing that might prevent the proper placement of the cuff on bare skin or be otherwise restricting around the upper arm, and to sit quietly for five minutes. The mid upper arm circumference is measured and the correct cuff size is selected from three to four available cuffs. If a simple mercury sphygmomanometer is used, the bell of the stethoscope is used for auscultation [29].

The EHES Manual has a template for a recording form for the blood pressure measurements. This form includes activities and behaviours of the participant before measurement, reasons for deviations from the standardized protocol, information about the measurement environment and measurement results [32].

\section{Training}

The national trainers participated in the three day European level training seminar organized by the EHES $\mathrm{RC}$. The key points of the measurements were discussed and practical training on real subjects was conducted. During the training, both mercury sphygmomanometer and oscillometric devices were used. The training included details about the posture of the subject during the measurement, how the arm circumference should be measured and the correct cuff size selected, instruction to be given to the participant (not to move or talk during the measurement), and how actual measurements should be taken. For the mercury sphygmomanometer, measurement training also included determination of the peak inflation level, the deflation rate to be used and determination of Korotkoff sounds (Phase I and Phase V). Training materials (presentations and videos) are available at the EHES web site [33].

The joint training session was followed by national training of the fieldwork personnel in each country. The 
duration and contents of the training varied both by country and the previous experience of the fieldwork staff.

\section{Evaluation \\ Site visits}

The success of the standardization was assessed during site visits by members of the EHES RC to observe the fieldwork in each country. The measurement environment (room temperature, disturbing noises, lighting, adequacy of the table and chair for the measurement), interaction between the subject and the measurer, the measurement procedure and equipment used for the blood pressure measurement (brand and type of the device, number of cuffs available) were recorded. Observations were documented in site visit reports and feedback to local survey organizers and fieldwork teams was provided.

\section{Retrospective data assessment}

A retrospective quality assessment of the measurements was conducted, based on national survey protocols and collected data. This assessment included comparison of the national survey protocols with the EHES protocol, evaluation of the proportion of missing data for each data item, proportion of identical sequential readings and the proportion of terminal digits. High proportions of identical sequential readings or terminal digit preference is an indicator of problems with the measurements, usually reflecting the lack of proper training.

\section{Results}

Most of the EHES pilot surveys were conducted in a clinical setting, either in the facilities of the local health care system or in temporary clinics set up specifically for the survey. In one survey, the measurements were conducted in the participants' home and another survey used a mobile examination unit. From the measurement environment, the room temperature was measured and recorded routinely in nine surveys. The average room temperature varied from $19.4^{\circ} \mathrm{C}$ to $25.0^{\circ} \mathrm{C}$, with relatively small variation within survey (Table 2). In some countries, occasional traffic noise outside the examination room or disturbances such as other personnel entering the room or a phone ringing during the measurements was observed during the site visits.

The instructions to record the activities and behaviour of the participant before the examination was added to the EHES protocol after most of the pilot surveys had already started. Therefore, in only five surveys were some of the participant's activities (smoking, physical activity, meals and drinking) before the examination recorded.

In all surveys, three blood pressure measurements were taken in a sitting posture from the right arm. In most surveys, occasional deviations for medical reasons were recorded. (Table 2) During the site visits, it was observed that the measurers sometimes forgot to check the position of the subject, resulting in an unsupported back and/or arm, or crossed legs, or the subjects were talking during or between the measurements. After these were pointed out, the problems were usually corrected immediately and special attention by the survey organizers was paid to these issues during the rest of the survey.

The simple mercury sphygmomanometer was used in three surveys and oscillometric devices in nine. For oscillometric devices, six different models from three manufacturers were used. Each model of the oscillometric devices had passed validation following the British Hypertension Society protocol [13], International protocol [14] or Advancement of Medical Instrumentation (AAMI) protocol [15] (Table 2).

In nine out of 12 surveys, more than one cuff size was available (Table 2). Arm circumference was measured in ten surveys (Table 3). When comparing measured arm circumferences to the size of the cuff used for the measurement, the miss-cuffing (use of too small or too large cuff) was observed only in 1-5\% of the subjects, except in one survey where only one cuff was available and $20 \%$ of subjects were miss-cuffed (Table 3). In three surveys which did not measure arm circumference, the occurrence of miss-cuffing would have been more likely to happen, especially if the used cuffs did not have markings to indicate correctness of the cuffs for the specific arm circumference. In all these three surveys, cuffs with indicators to assess the correctness of the cuff size were used.

The proportion of identical sequential measurements was lower between the first and the second measurement than between the second and the third measurement for both systolic and diastolic blood pressure in three surveys using simple mercury sphygmomanometers. In each survey, the proportion of identical readings was higher for diastolic than for systolic blood pressure. Overall, the proportion of identical sequential measurements was high only in two surveys ( $28 \%$ or over) using simple mercury sphygmomanometer (Table 3 ).

Terminal digit preference was not a problem when oscillometric devices were used. In one of the three surveys which used mercury sphygmomanometers, a clear terminal digit preference for zero was seen for both systolic and diastolic blood pressure (Tables 4 and 5).

\section{Discussion}

Reliable population level information on blood pressure levels and prevalence of hypertension are needed for developing evidence based policy and planning prevention activities as well as for research. Obtaining such information is challenging, since the measurement environment, behaviour of the subject, measurement protocol, device used for the measurements and the 
Table 2 Blood pressure measurement protocols used in EHES pilot surveys

\begin{tabular}{|c|c|c|c|c|c|c|c|c|c|}
\hline $\begin{array}{l}\text { Pilot } \\
\text { survey }\end{array}$ & $\begin{array}{l}\text { Number of } \\
\text { participants }\end{array}$ & Survey period & $\begin{array}{l}\text { Mean room } \\
\text { temperature }{ }^{\circ} \mathrm{C} \\
(\min , \max )\end{array}$ & Arm used & $\begin{array}{l}\text { Posture of the } \\
\text { subject during } \\
\text { the measurement }\end{array}$ & Device type & Device model & $\begin{array}{l}\text { Used cuff sizes } \\
\text { (recommended arm } \\
\text { circumference) }\end{array}$ & $\begin{array}{l}\text { Side of stethoscope } \\
\text { when auscultation } \\
\text { method used }\end{array}$ \\
\hline A & 123 & May-Jun 2011 & $22.3(21,24)$ & Right & Sitting & $\begin{array}{l}\text { Mercury } \\
\text { sphygmomanometer }\end{array}$ & $\begin{array}{l}\text { Riester diplomat } \\
\text { presometer }\end{array}$ & $22-32 \mathrm{~cm}$ and $33-41 \mathrm{~cm}$ & Bell \\
\hline B & 111 & Apr-Jul 2011 & $25.0(18,33)$ & Right $^{1,2}$ & Sitting 3,4 & $\begin{array}{l}\text { Mercury } \\
\text { sphygmomanometer }\end{array}$ & $\begin{array}{l}\text { Riester diplomat } \\
\text { presometer }\end{array}$ & $\begin{array}{l}17-26 \mathrm{~cm}, 24-32 \mathrm{~cm}, \\
32-48 \mathrm{~cm}\end{array}$ & Diaphragm \\
\hline C & 393 & Oct 2010-Jan 2011 & $22.8(21,26)$ & Right & Sitting & $\begin{array}{l}\text { Mercury } \\
\text { sphygmomanometer }\end{array}$ & Riva Rocci & $\leq 34 \mathrm{~cm},>34 \mathrm{~cm}$ & Bell \\
\hline D & 183 & Nov 2010-Jan 2011 & $23.3(22,24)$ & Right $^{1,2}$ & Sitting ${ }^{3,4}$ & Oscillometric device & Omron i-c10 & $22-42 \mathrm{~cm}$ & not relevant \\
\hline E & 305 & May-Jun 2011 & $23.0(16,29)$ & Right $^{1}$ & Sitting & Oscillometric device & Omron i-c10 & $22-42 \mathrm{~cm}$ & not relevant \\
\hline $\mathrm{F}$ & 131 & Nov 2010-Feb 2011 & $23.2(22,25)$ & Right $^{1,2}$ & Sitting 3,4 & Oscillometric device & Omron i-c10 & $22-42 \mathrm{~cm},>42 \mathrm{~cm}$ & not relevant \\
\hline G & 1302 & Oct-Dec 2010 & \# & Right $^{1}$ & Sitting & Oscillometric device & Omron M6 & $\begin{array}{l}17-22 \mathrm{~cm}, 22-32 \mathrm{~cm} \\
32-42 \mathrm{~cm}\end{array}$ & not relevant \\
\hline $\mathrm{H}$ & 137 & May-Jul 2010 & $\#$ & Right $^{1,2}$ & Sitting $^{3}$ & Oscillometric device & Omron M6 & $22-32 \mathrm{~cm}$ & not relevant \\
\hline I & 168 & Jan-Mar 2011 & $21.3(16,25)$ & Right $^{1,2}$ & Sitting ${ }^{3,4}$ & Oscillometric device & Omron 705IT & $\begin{array}{l}\leq 21 \mathrm{~cm}, 22-31 \mathrm{~cm}, \\
\geq 32 \mathrm{~cm}\end{array}$ & not relevant \\
\hline J & 922 & Jan-May 2011 & $19.4(12,25)$ & Right $^{1}$ & Sitting & Oscillometric device & Omron HEM-907 & $\begin{array}{l}17-22 \mathrm{~cm}, 22-32 \mathrm{~cm} \\
32-42 \mathrm{~cm}\end{array}$ & not relevant \\
\hline K & 190 & Jun-Jul 2011 & $23.4(19,32)$ & Right $^{1}$ & Sitting $^{3}$ & Oscillometric device & $\begin{array}{l}\text { Datascope } \\
\text { Accutorr Plus }\end{array}$ & $\begin{array}{l}13-20 \mathrm{~cm}, 21-27 \mathrm{~cm} \\
28-35 \mathrm{~cm}, 36-46 \mathrm{~cm}\end{array}$ & not relevant \\
\hline L & 162 & Nov-Dec 2010 & $\#$ & Right $^{1}$ & Sitting & Oscillometric device & Citizen $\mathrm{CH}-432 \mathrm{~B}$ & $\begin{array}{l}20-26 \mathrm{~cm}, 25-34 \mathrm{~cm}, \\
32-43 \mathrm{~cm}\end{array}$ & not relevant \\
\hline
\end{tabular}

\# Room temperature not measured, ${ }^{1}$ If the measurement was done on the left arm that was recorded, ${ }^{2}$ The reason for use of left arm was also recorded, ${ }^{3}$ If the measurement was done in the supine posture, that was recorded, ${ }^{4}$ The reason why the measurement was done in the supine posture was also recorded. 
Table 3 Recording of cuff size used and measured arm circumference, mean arm circumference, proportion of miss-cuffed subject, and proportion of identical readings

\begin{tabular}{|c|c|c|c|c|c|c|c|c|}
\hline \multirow[t]{2}{*}{$\begin{array}{l}\text { Pilot } \\
\text { survey }\end{array}$} & \multirow[t]{2}{*}{$\begin{array}{l}\text { Recorded } \\
\text { cuff size } \\
\text { used }\end{array}$} & \multirow{2}{*}{$\begin{array}{l}\text { Arm circumference } \\
\text { measured and recorded } \\
\text { ( } M=\text { measured, not } \\
\text { recorded, } B=\text { measured } \\
\text { and recorded, } N=\text { Not } \\
\text { measured) }\end{array}$} & \multirow[t]{2}{*}{$\begin{array}{l}\text { Mean arm } \\
\text { circumference } \\
\text { (min,max) }\end{array}$} & \multirow{2}{*}{$\begin{array}{l}\text { Proportion of miss-cuffed } \\
\text { subject (based on optimal } \\
\text { arm circumference reported } \\
\text { on the cuff) }\end{array}$} & \multicolumn{2}{|c|}{$\begin{array}{l}\text { Proportion of identical } \\
\text { readings between } 1 \text { st and } \\
\text { 2nd measurement }\end{array}$} & \multicolumn{2}{|c|}{$\begin{array}{l}\text { Proportion of identical } \\
\text { readings between } 2 n d \\
\text { and } 3 \text { rd measurement }\end{array}$} \\
\hline & & & & & $\mathrm{SBP}$ & DBP & $\mathrm{SBP}$ & DBP \\
\hline A & No & B & 30.8 cm $(24.5,43.5)$ & $\#$ & $8 \%$ & $29 \%$ & $16 \%$ & $28 \%$ \\
\hline B & Yes & B & 31.6 cm $(23.0,48.0)$ & $1 \%$ & $10 \%$ & $29 \%$ & $31 \%$ & $41 \%$ \\
\hline C & Yes & B & $28.3 \mathrm{~cm}(20.0,40.0)$ & $0 \%$ & $10 \%$ & $13 \%$ & $19 \%$ & $19 \%$ \\
\hline D & Yes & $\mathrm{N}$ & $\S$ & $\#$ & $4 \%$ & $10 \%$ & $7 \%$ & $12 \%$ \\
\hline$E$ & Yes & B & $29.9 \mathrm{~cm}(22.0,41.5)$ & $0 \%$ & $5 \%$ & $9 \%$ & $6 \%$ & $11 \%$ \\
\hline $\mathrm{F}$ & Yes & B & $28.9 \mathrm{~cm}(21.0,41.5)$ & $2 \%$ & $3 \%$ & $9 \%$ & $9 \%$ & $11 \%$ \\
\hline G & Yes & M & $\S$ & $\#$ & $7 \%$ & $12 \%$ & $8 \%$ & $13 \%$ \\
\hline $\mathrm{H}$ & Yes & B & 30.1 cm (21.0,48.0) & $20 \%$ & $3 \%$ & $8 \%$ & $5 \%$ & $9 \%$ \\
\hline । & Yes & B & 30.9 cm $(22.0,46.0)$ & $0 \%$ & $8 \%$ & $10 \%$ & $8 \%$ & $10 \%$ \\
\hline J & Yes & $\mathrm{N}$ & $\S$ & $\#$ & $6 \%$ & $14 \%$ & $9 \%$ & $15 \%$ \\
\hline K & Yes & B & $30.4 \mathrm{~cm}(21.5,43.3)$ & $5 \%$ & $4 \%$ & $10 \%$ & $7 \%$ & $10 \%$ \\
\hline L & Yes & B & $30.4 \mathrm{~cm}(24.0,40.0)$ & $1 \%$ & $5 \%$ & $9 \%$ & $5 \%$ & $11 \%$ \\
\hline
\end{tabular}

§ Arm circumference not measured, \# Not possible to calculate. 
Table 4 Proportion of terminal digits for systolic blood pressure

\begin{tabular}{|c|c|c|c|c|c|c|c|c|c|c|c|c|}
\hline \multirow[t]{2}{*}{ Device } & \multirow[t]{2}{*}{ Survey } & \multicolumn{10}{|c|}{ Terminal digit (\%) } & \multirow{2}{*}{$\begin{array}{l}p \text {-value } \\
\text { for } \chi^{2} \text {-tes }\end{array}$} \\
\hline & & 0 & 1 & 2 & 3 & 4 & 5 & 6 & 7 & 8 & 9 & \\
\hline \multirow[t]{3}{*}{ Mercury sphygmomanometer } & A & 22 & 0 & 23 & 0 & 21 & 0 & 18 & 0 & 17 & 0 & 0.4488 \\
\hline & $\mathrm{B}$ & 33 & 6 & 9 & 3 & 5 & 22 & 5 & 4 & 9 & 4 & $<0.0001$ \\
\hline & C & 18 & 0 & 20 & 0 & 20 & 0 & 19 & 0 & 23 & 0 & 0.1352 \\
\hline \multirow[t]{3}{*}{ Omron i-C10 } & $\mathrm{D}$ & 9 & 11 & 11 & 9 & 10 & 11 & 11 & 9 & 11 & 9 & 0.9826 \\
\hline & $E$ & 11 & 10 & 10 & 9 & 10 & 10 & 9 & 11 & 10 & 9 & 0.7936 \\
\hline & $\mathrm{F}$ & 12 & 9 & 11 & 7 & 11 & 7 & 6 & 13 & 15 & 9 & 0.0007 \\
\hline \multirow[t]{2}{*}{ Omron M6 } & G & 11 & 10 & 9 & 10 & 11 & 10 & 10 & 10 & 9 & 10 & 0.0464 \\
\hline & $\mathrm{H}$ & 10 & 8 & 12 & 8 & 9 & 11 & 9 & 13 & 12 & 8 & 0.2126 \\
\hline \multirow[t]{2}{*}{ Other Omron models } & । & 10 & 8 & 12 & 9 & 11 & 8 & 9 & 9 & 11 & 12 & 0.4071 \\
\hline & J & 11 & 10 & 12 & 10 & 9 & 9 & 9 & 10 & 10 & 10 & 0.1308 \\
\hline \multirow[t]{2}{*}{ Other brands } & K & 9 & 11 & 9 & 12 & 11 & 10 & 13 & 7 & 9 & 9 & 0.1753 \\
\hline & $L$ & 10 & 10 & 13 & 10 & 9 & 10 & 8 & 9 & 9 & 11 & 0.5258 \\
\hline
\end{tabular}

observers can each affect the accuracy of the blood pressure measurements.

To overcome the challenges, the EHES Pilot Project prepared a European level standardized protocol for blood pressure measurement, a training programme and quality control to support the collection of high quality and comparable blood pressure data across populations. The protocol was tested in 12 pilot surveys with encouraging results.

In general, the room temperature could be standardized to a comfortable level and it was possible to eliminate outside disturbance. This is easiest when examinations are carried out in existing health care facilities designed for medical examinations or in a mobile unit especially designed for this purpose. When temporary examination clinics are set up for the survey, it may be difficult to find suitable locations which are available for a relatively short period of time. It is more difficult to standardize the measurement environment when the measurements are conducted at the participants' home. In this case, the survey organizers cannot control the room temperature or possible disturbances during the measurement. Therefore it is particularly important to record the room temperature and possible disturbances during the measurement.

Controlling the behaviour of the participant before the examination requires clear instructions for the survey invitees. The person welcoming the participant to the examination centre or staff taking the blood pressure measurements should check that the participant does not have an uncomfortably full bladder before the blood pressure measurement begins. Information on activities before measurement should be recorded.

Table 5 Proportion of terminal digits for diastolic blood pressure

\begin{tabular}{|c|c|c|c|c|c|c|c|c|c|c|c|c|}
\hline \multirow[t]{2}{*}{ Device } & \multirow[t]{2}{*}{ Survey } & \multicolumn{10}{|c|}{ Terminal digit (\%) } & \multirow{2}{*}{$\begin{array}{l}\text { p-value } \\
\text { for } x^{2} \text {-test }\end{array}$} \\
\hline & & 0 & 1 & 2 & 3 & 4 & 5 & 6 & 7 & 8 & 9 & \\
\hline \multirow[t]{3}{*}{ Mercury sphygmomanometer } & $A$ & 21 & 0 & 19 & 0 & 26 & 0 & 18 & 0 & 16 & 0 & 0.0392 \\
\hline & B & 35 & 8 & 8 & 5 & 7 & 17 & 6 & 5 & 6 & 4 & $<0.0001$ \\
\hline & C & 22 & 0 & 17 & 0 & 19 & 0 & 19 & 0 & 23 & 0 & 0.0317 \\
\hline \multirow[t]{3}{*}{ Omron i-C10 } & D & 15 & 12 & 9 & 9 & 8 & 9 & 10 & 10 & 8 & 9 & 0.0122 \\
\hline & $E$ & 11 & 9 & 9 & 9 & 11 & 10 & 9 & 12 & 10 & 11 & 0.2596 \\
\hline & $\mathrm{F}$ & 11 & 10 & 7 & 10 & 9 & 12 & 11 & 10 & 9 & 10 & 0.4936 \\
\hline \multirow[t]{2}{*}{ Omron M6 } & G & 10 & 9 & 10 & 10 & 10 & 10 & 10 & 10 & 10 & 10 & 0.7859 \\
\hline & $\mathrm{H}$ & 9 & 9 & 10 & 12 & 10 & 10 & 10 & 11 & 10 & 9 & 0.9850 \\
\hline \multirow[t]{2}{*}{ Other Omron models } & 1 & 12 & 12 & 10 & 11 & 12 & 9 & 9 & 9 & 9 & 8 & 0.1123 \\
\hline & $J$ & 11 & 9 & 10 & 11 & 9 & 10 & 10 & 11 & 10 & 9 & 0.4148 \\
\hline \multirow[t]{2}{*}{ Other brands } & K & 11 & 11 & 10 & 12 & 9 & 10 & 8 & 8 & 9 & 12 & 0.2285 \\
\hline & $L$ & 11 & 9 & 11 & 9 & 11 & 9 & 9 & 11 & 11 & 9 & 0.9030 \\
\hline
\end{tabular}


The importance of standardized measurement procedures in multicentre and international studies has been reported [12,34]. The EHES Pilot Project demonstrated that a standardized protocol is a feasible tool for minimizing variation due to measurement technique. In addition, the measurers must be trained properly. This has been shown by the National Health and Nutrition Examination Survey (NHANES) of the United States [35] and the WHO MONICA Project [36], where extensive training has been found to be crucial for the success of standardization. Similar results have been reported from hypertension studies [34,37].

To evaluate the use of a standardized protocol in the field, monitoring is required during the fieldwork. These monitoring visits should be done on a regular basis to observe how fieldwork teams conduct measurements, how they interact with survey invitees and also how they interact with each other. The interval between monitoring visits depends on the duration of the fieldwork. When the fieldwork is conducted within a few months, at least one monitoring visit should be done at the beginning of the fieldwork and one during the remaining fieldwork period. In surveys with a longer fieldwork period, the interval of the monitoring visits should be conducted so that they take into account changes of examination sites and also possible changes in the fieldwork personnel. Depending on the survey, these visits can be every 2-4 months. Also, re-training or refresher sessions, during which standardized measurement protocols are gone through and measurements are conducted under supervision, are needed to maintain the level of standardization, especially if the fieldwork last several months or years.

Traditionally, the mercury sphygmomanometer has been considered as the 'gold standard' for blood pressure measurement. In Europe, the use of mercury sphygmomanometers in HESs has declined during the past decades. In future, all European HESs will have to use devices other than mercury sphygmomanometers, as the EU regulation 847/2012 banned the sale of mercury sphygmomanometers from 10 April 2014 onwards [38]. It has been shown that changing from mercury sphygmomanometers to non-mercury devices (oscillometric or aneroid devices) affects the monitoring of blood pressure levels and hypertension prevalence [39]. With changing devices, it is important to conduct validation studies to obtain calibration estimates to ensure comparability of results within and between populations.

A variety of oscillometric devices for blood pressure measurement is on the market. Many of them have passed at least one of the validation tests based on the British Hypertension Society protocol [13], International protocol of the European Society of Hypertension [14] or Association for the Advancement of Medical
Instrumentation (AAMI) protocol [15]. These validation protocols are designed to evaluate the accuracy of the device for clinical practice. However, the allowed deviations are too large for epidemiological studies. The information about the devices which have passed the validation can be found for example on the British Hypertension Society web site at http://www.bhsoc.org/ bp-monitors/bp-monitors and the dabl ${ }^{\circ}$ Educational Trust web site at http://www.dableducational.org/sphygmomanometers.html. Comparison of the different oscillometric devices is difficult, since their algorithms used for determination of the systolic and diastolic blood pressure are not openly accessible and these are likely to change over time as the measurement devices are improved. This also makes it difficult to replicate the validation studies for the older models. Therefore, the auscultation method with calibrated devices will remain superior and should be considered as 'gold standard' also in future. For the auscultation method, there are validated alternatives to the mercury sphygmomanometer [40,41].

The importance of correct cuff size for the accuracy of the blood pressure measurement has been emphasized. Use of too large a cuff can result up to $10-30 \mathrm{mmHg}$ lower systolic and diastolic blood pressure readings and on the other hand, use of too small a cuff to $3-12 \mathrm{mmHg}$ higher systolic and 2-8 $\mathrm{mmHg}$ higher diastolic blood pressure readings [11]. Regarding cuff size, the width of the cuff bladder should be at least $40 \%$ of the arm circumference and the length at least $80 \%$ to minimize the error due to incorrect cuff size [42]. As shown by the EHES Pilot results, there is a large variety of cuff sizes on the market. Each manufacturer has its own cuffs. Some manufacturers have provided so called 'universal' cuffs, which should be used for a wide range of arm circumferences $(22-42 \mathrm{~cm})$. Variation in cuff sizes should not be a problem as long as the manufacturers provide several different cuff sizes and the appropriate cuff size is used for each participant.

Miss-cuffing was not a major problem in the EHES pilot. Some countries encountered problems in obtaining more than one cuff size (universal cuff) for their oscillometric device through their national supplier.

Observer error can be minimized when oscillometric devices are used. For mercury sphygmomanometers, minimizing the observer error requires thorough practical training $[43,44]$.

The final decision on the blood pressure measurement protocol to be used in national HES in Europe is made by each country. The actual deviations between protocols used were small and could be easily corrected; in most cases, differences were only in the devices used. These and other possible deviations were usually caused by the need to follow trends from past surveys within the country. Nevertheless, there is a shared desire for 
comparability of the blood pressure measurement results between countries. This can be obtained through a joint protocol. The EHES blood pressure measurement protocol was followed well in all 12 EHES pilot surveys, and the external quality control helped to minimize observer errors. In the countries which had an on-going full-size national HES, the EHES protocol was also followed well. These surveys had based their blood pressure measurement protocols for previous European level standards of the European Health Risk Monitoring (EHRM) Project, which was the base for the EHES protocol [45].

\section{Conclusions}

Our experience from the EHES Pilot Project is in line with the results of previous studies showing that blood pressure measurements can be standardized across countries and over time. This requires a detailed, standardized measurement protocol; adequate training; and monitoring during the fieldwork as well as retrospective quality assessment. However, the recent EU regulation banning the sale of the mercury sphygmomanometers in European Union Member States [38] and the differences between the oscillometric devices have set new challenges for the standardization of blood pressure measurement.

\section{Appendix 1 Ethical committees providing the approval for the surveys}

Czech Republic: Ethical Committee of the National Institute of Public Health, Prague.

Finland: Helsingin ja Uudenmaan sairaanhoitopiiri, Koordinoiva eettinen toimikunta, Helsinki.

Germany: Ethik Kommission, Charité, Universitätsmedizin, Berlin.

Greece: Ethical Committee of Hellenic Health Foundation, Athens.

Italy: Ethical Committee of the Istituto Superiore di Sanità, Rome.

Malta: Health Ethics Committee, Department of Health Information \& Research.

Netherlands: Medisch Ethische Toetsingscommissie, Universitair Medisch Centrum, Utrecht.

Norway: The Regional Committee for Medical and Health Research Ethics REK North.

Poland: Terenowej Komisji Bioetycznej przy Instytucie Kardiologii.

Portugal: Comissão de Ética, Instituto Nacional de Saúde, Doctor Ricardo Jorge.

Slovakia: Ethical Committee, Regional Authority of Public Health (RAPH), Banská Bystrica.

UK/England: Oxfordshire REC A, National Research Ethics Service, NHS.

\section{Appendix 2 Sites and key personnel contributing to the EHES Pilot Project}

Czech Republic: National Institute of Public Health, Prague: Ruzena Kubinova, Nada Capkova, Jana Kratenova and Michala Lustigova.

Finland: National Institute for Health and Welfare (THL). EHES Reference Centre: Kari Kuulasmaa, Hanna Tolonen, Katri Kilpeläinen, Päivikki Koponen, Sanna Ahonen, Johanna Mäki-Opas, Ari Haukijärvi, Tarja Palosaari, Georg Alfthan, Jari Kirsilä.

National pilot survey: Satu Männistö, Katja Borodulin, Liisa Saarikoski, Anne Juolevi, Markku Peltonen, Tiina Laatikainen, Erkki Vartiainen, Jouko Sundvall, Laura Lund, Antti Jula, Eija Purkamo.

Germany: Robert Koch Institute, Berlin. For the DEGS Study Team: Antje Gösswald, Cornelia Lange, Panagiotis Kamtsiuris.

Greece: Hellenic Health Foundation, Athens. Antonia Trichopoulou, Valentini Konstantinidou, Androniki Naska, Dimosthenis Zilis, Vardis Dilis, George Adarakis, Ioulia Goufa, Georgia Stasinopoulou, Elisabeth Valanou, Perikles Karathanasis, Nikolaos Bilalis, Philippos Orfanos, Tina Karapetyan, Despina Oikonomidou, Eirini Frangogeorgi and Konstantinos Mine.

Italy: Istituto Superiore di Sanità, Rome. EHES Reference Centre: Susanna Conti, Mark Kanieff.

National Pilot Survey: Luigi Palmieri, Chiara Donfrancesco, Cinzia Lo Noce, Francesco Dima, Amalia De Curtis, Licia Iacoviello, Diego Vanuzzo, Simona Giampaoli.

Malta: Department of Health Information \& Research, Gwardamangia: Neville Calleja, Dorothy Gauci.

The Netherlands: National Institute of Public Health and the Environment (RIVM), Bilthoven: W.M. Monique Verschuren.

Norway: Norwegian Institute of Public Health: Grethe S. Tell, Patricia Schreuder, Sidsel Graff-Iversen, Nina Hovland; University of Bergen: Kristin Klock.

Statistics Norway. EHES Reference Centre: Johan Heldal, Susie Jentoft.

Poland: The Cardinal Stefan Wyszynski Institute of Cardiology, Warsaw: Grażyna Broda, Aleksandra Piwonska, Jerzy Piwoński, Paweł Kurjata, Walerian Piotrowski, Maria Polakowska, Anna Waśkiewicz, Elzbieta Sygnowska.

Portugal: Instituto Nacional de Saúde Dr. Ricardo Jorge, Lisbon: Carlos Dias, Ana Paola Gil.

Slovakia: Regional Authority of Public Health, Banská Bystrica. Maria Avdicova, Katarina Francisciova, Jana Namesna, Silvia Kontrosova.

UK: UCL (University College London), London: Jennifer Mindell, Nicola Shelton, Barbara Carter-Szatynska, Alison Moody. 
Health and Social Care Information Centre, London: Rachel Craig, Susan Nunn, Deanna Pickup, Chloe Robinson.

\section{The NHS Information Centre: Steve Webster, Victoria Cooper.}

\section{Competing interests}

The authors declare that they have no competing interests.

\section{Authors' contributions}

$H T$, PK and KK planned the outline of the manuscript. HT and TP did the data analysis. AN, SM and GB were involved in the acquisition of data. All authors contributed to the interpretation of the data, drafting of the manuscript and have provided their final approval for the work. All authors have also provided their agreement to be accountable for all aspects of the work.

\section{Acknowledgement}

The EHES Pilot Project was made possible through collaboration of the staff members of the EHES Reference Centre and EHES Pilot Countries (Appendix 2). The EHES Pilot Project has received funding from the European Commission/ DG Sanco (Service Contract SANCO/2008/C2/02-SI2.538218 EHES and Agreement no - 200923 01). The views expressed here are those of the authors and they do not represent the Commission's official position.

\section{Author details}

'Department of Health, National Institute for Health and Welfare, Helsinki, Finland. ${ }^{2}$ Hellenic Health Foundation, Athens, Greece and Department of Hygiene, Epidemiology and Medical Statistics, University of Athens Medical School, Athens, Greece. ${ }^{3}$ The Cardinal Stefan Wyszynski Institute of Cardiology, Warsaw, Poland.

Received: 20 November 2013 Accepted: 18 March 2015 Published online: 10 April 2015

\section{References}

1. Rose GA, Khaw K-T, Marmot MG. Rose's strategy of preventive medicine: the complete original text. New edition. Oxford; New York: Oxford University Press; 2008.

2. Kawahara J, Sano H, Fukuzaki H, Saito K, Hirouchi H. Acute effects of exposure to cold on blood pressure, platelet function and sympathetic nervous activity in humans. Am J Hypertens. 1989;2(9):724-6.

3. Campbell NR, McKay DW, Chockalingam A, Fodor JG. Errors in assessment of blood pressure: patient factors. Can J Public Health. 1994;85 Suppl 2:S12-7.

4. Handler J. The importance of accurate blood pressure measurement. Perm J. 2009;13(3):51-4

5. Campbell NR, McKay DW. Accurate blood pressure measurement: why does it matter? CMAJ. 1999:161(3):277-8.

6. Gould BA, Hornung RS, Kieso HA, Altman DG, Raftery EB. Is the blood pressure the same in both arms? Clin Cardiol. 1985;8(8):423-6.

7. Jamieson MJ, Webster J, Philips S, Jeffers TA, Scott AK, Robb OJ, et al. The measurement of blood pressure: sitting or supine, once or twice? J Hypertens. 1990;8(7):635-40

8. Keele-Smith R, Price-Daniel C. Effects of crossing legs on blood pressure measurement. Clin Nurs Res. 2001;10(2):202-13.

9. Netea RT, Lenders JW, Smits P, Thien T. Arm position is important for blood pressure measurement. J Hum Hypertens. 1999:13(2):105-9.

10. Netea RT, Smits P, Lenders JW, Thien T. Does it matter whether blood pressure measurements are taken with subjects sitting or supine? J Hypertens. 1998;16(3):263-8.

11. O'Brien E, Asmar R, Beilin L, Imai Y, Mallion JM, Mancia G, et al. European society of hypertension recommendations for conventional, ambulatory and home blood pressure measurement. J Hypertens. 2003;21(5):821-48.

12. Schulze MB, Kroke A, Saracci R, Boeing $H$. The effect of differences in measurement procedure on the comparability of blood pressure estimates in multi-centre studies. Blood Press Monit. 2002;7(2):95-104.

13. O'Brien E, Petrie J, Little W, de Swiet M, Padfield P. The British hypertension society protocol for the evaluation of blood pressure measuring devices. J Hypertens. 1993;11 Suppl 2:S43-62.

14. O'Brien E, Atkins N, Stergiou G, Karpettas N, Parati G, Asmar R, et al. European society of hypertension international protocol revision 2010 for the validation of blood pressure measuring devices in adults. Blood Press Monit. 2010:15(1):23-38.

15. Association for the Advancement of Medical Instrumentation. Non-invasive sphygmomanometers - part 2: clinical validation of automated measurement type. ANSI/AAMI/ISO 81060-2. Association for the Advancement of Medical Instrumentatio, 2013.

16. Mauro AMP. Effects of bell versus diaphragm on indirect blood-pressure measurement. Heart Lung. 1988;17(5):489-94.

17. Kantola I, Vesalainen R, Kangassalo K, Kariluoto A. Bell or diaphragm in the measurement of blood pressure? J Hypertens. 2005:23(3):499-503.

18. Coleman AJ, Steel SD, Ashworth M, Vowler SL, Shennan A. Accuracy of the pressure scale of sphygmomanometers in clinical use within primary care. Blood Press Monit. 2005;10(4):181-8.

19. de Greeff A, Lorde I, Wilton A, Seed P, Coleman AJ, Shennan AH. Calibration accuracy of hospital-based non-invasive blood pressure measuring devices. J Hum Hypertens. 2010;24(1):58-63.

20. Rose G. Standardisation of observers in blood-pressure measurement. Lancet. 1965;1(7387):673-4.

21. Beevers G, Lip GY, O'Brien E. ABC of hypertension: blood pressure measurement. Part II-conventional sphygmomanometry: technique of auscultatory blood pressure measurement. BMJ. 2001;322(7293):1043-7.

22. de Lusignan S, Belsey J, Hague N, Dzregah B. End-digit preference in blood pressure recordings of patients with ischaemic heart disease in primary care. J Hum Hypertens. 2004;18(4):261-5.

23. Hessel PA. Terminal digit preference in blood pressure measurements: effects on epidemiological associations. Int J Epidemiol. 1986;15(1):122-5.

24. Neufeld PD, Johnson DL. Observer error in blood pressure measurement. CMAJ. 1986;135(6):633-7.

25. Turner MJ, Baker AB, Kam PC. Effects of systematic errors in blood pressure measurements on the diagnosis of hypertension. Blood Press Monit. 2004;9(5):249-53.

26. Pickering TG, Hall JE, Appel LJ, Falkner BE, Graves J, Hill MN, et al. Recommendations for blood pressure measurement in humans and experimental animals: Part 1: blood pressure measurement in humans: a statement for professionals from the subcommittee of professional and public education of the American Heart Association Council on high blood pressure research. Hypertension. 2005;45(1):142-61.

27. WHO MONICA Project. MONICA manual, part III: population survey, section 1: population survey data component. Volume 2012. 1997. Available at URL:http://www.thl.fi/publications/monica/manual/part3/iii-1.htm, URN: NBN:fi-fe1998113

28. Luepker RV, Evans A, McKeigue P, Srinath Reddy K. Cardiovascular survey methods. 3rd ed. Geneva: World Health Organization; 2004

29. Tolonen H, Koponen P. 5.1 Blood pressure in Tolonen H. (Ed.) EHES manual, part B. Fieldwork procedures. In: Tolonen $\mathrm{H}$, editor. EHES manual, part B fieldwork procedures. Helsinki: National Institute for Health and Welfare; 2013

30. Kuulasmaa K, Tolonen H, Koponen P, Kilpelainen K, Avdicova M, Broda G, et al. An overview of the European health examination survey pilot joint action. Arch Public Health. 2012;70(1):20.

31. Tolonen H. EHES manual. Part A. Planning and preparing for the survey. Volume directions 2013 001. Helsinki: National Institute for Health and Welfare; 2013

32. Tolonen H. EHES manual. Part B. Fieldwork procedures. Volume directions 2013 002. Helsinki: National Institute for Health and Welfare; 2013.

33. Training materials. [http://www.ehes.info/training_materials/index.htm]

34. Ataman SL, Cooper R, Rotimi C, McGee D, Osotimehin B, Kadiri S, et al. Standardization of blood pressure measurement in an international comparative study. J Clin Epidemiol. 1996;49(8):869-77.

35. Ostchega Y, Prineas RJ, Paulose-Ram R, Grim CM, Willard G, Collins D. National health and nutrition examination survey 1999-2000: effect of observer training and protocol standardization on reducing blood pressure measurement error. J Clin Epidemiol. 2003:56(8):768-74.

36. Hense HW, Koivisto AM, Kuulasmaa K, Zaborskis A, Kupsc W, Tuomilehto J. Assessment of blood pressure measurement quality in the baseline surveys of the WHO MONICA project. J Hum Hypertens. 1995;9(12):935-46.

37. O'Brien E, Mee F, Tan KS, Atkins N, Omalley K. Training and assessment of observers for blood-pressure measurement in hypertension research. J Hum Hypertens. 1991:5(1):7-10.

38. European Commission. Commission Regulation (EU) No 847/2012 on 19 September 2012 amending Annex XVII to Regulation (EC) No 1907/2006 of the European Parliament and of the council on the registration, evaluation, 
authorisation and restriction of chemicals (REACH) as regards mercury. In 847/2012. Edited by European Commission. Off J Eur Union, L253, 20.9.2012.

39. Ostchega Y, Zhang G, Sorlie P, Hughes JP, Reed-Gillette DS, Nwankwo T, et al. Blood pressure randomized methodology study comparing automatic oscillometric and mercury sphygmomanometer devices: national health and nutrition examination survey, 2009-2010. Natl Health Stat Report. 2012: (59):1-15.

40. Pruijm MT, Wuerzner G, Glatz N, Alwan H, Ponte B, Ackermann D, et al. A new technique for simultaneous validation of two manual nonmercury auscultatory sphygmomanometers (A\&D UM-101 and Accoson Greenlight 300) based on the International protocol. Blood Press Monit. 2010;15(6):322-5.

41. Stergiou GS, Karpettas N, Kollias A, Destounis A, Tzamouranis D. A perfect replacement for the mercury sphygmomanometer: the case of the hybrid blood pressure monitor. J Hum Hypertens. 2012;26(4):220-7.

42. Frohlich ED, Grim CM, Labarthe DR, Maxwell MH, Perloff D, Weidman WH. Recommendations for human blood pressure determination by sphygmomanometers. Report of a special task force appointed by the steering committee, American Heart Association. Hypertension. 1988;11(2):209A-22A.

43. Fornells JM, Borras JM, Balaguer-Vintro I. The preference for the final digits in blood pressure determination: a continuing education experience. Aten Primaria. 1990;7(2):102-5.

44. Kolb C, Huss R, Mengden T, Vetter W. How reliable is conventional blood pressure registration? Comparison with a semi-automatic device. Schweiz Rundsch Med Prax. 1991;80(12):286-90.

45. Tolonen H, Kuulasmaa K, Laatikainen T, Wolf H, the European Health Risk Monitoring Project. Recommendations for indicators, international collaboration, protocol and manual of operations for chronic disease risk factor surveys. Helsinki: Finnish National Public Health Institute; 2002.

\section{Submit your next manuscript to BioMed Central and take full advantage of:}

- Convenient online submission

- Thorough peer review

- No space constraints or color figure charges

- Immediate publication on acceptance

- Inclusion in PubMed, CAS, Scopus and Google Scholar

- Research which is freely available for redistribution 